\title{
Educação ambiental e as dimensões cognitiva e afetiva do trabalho com valores: produzindo sentidos
}

\author{
Environmental education and the cognitive and affective \\ dimensions from the work with values: the production \\ of meanings
}

Thais Cristiane Degasperi ${ }^{1}$. Dalva Maria Bianchini Bonotto ${ }^{1}$

\begin{abstract}
Resumo: A partir do contexto de crise socioambiental, vislumbramos a contribuição da Educação Ambiental como forma de enfrentamento e proposição de novos caminhos para a relação sociedadenatureza. Propomos o resgate e/ou construção de novos valores, que devem envolver afetos e reflexões, projetando-se em novos padrões de relação do indivíduo com o ambiente e a sociedade. Em uma perspectiva qualitativa, analisamos os sentidos produzidos nos diálogos empreendidos em episódios de ensino ocorridos entre professora e alunos a respeito da temática ambiental e valores, considerando, especialmente, as dimensões cognitiva e afetiva. Verificamos que a articulação dessas dimensões, nos episódios, implicou em um trabalho com valores significativo, ampliando as possibilidades de sua construção. Entre a apreciação estética de uma área verde e a proposição de um dilema a seu respeito há a intencionalidade do docente, limites e possibilidades dessas atividades, com os sentidos que nelas são produzidos, constituindo-se novos discursos para a relação sociedade-natureza.
\end{abstract}

Palavras-chave: Educação ambiental. Cognição. Afetividade. Produção de sentidos.

\begin{abstract}
From the context of the socio-environmental crisis, we envisage the contribution of the Environmental Education as a way of confronting and proposing of new ways for the relation between society and nature. We propose the reintroduction and/or construction of new values that must involve affective and reflective aspects in order to project new patterns of individual relations with the nature and society. In a qualitative perspective, we analyzed the meaning making in the dialogues in episodes of teaching that occurred between the teacher and the students regarding environmental themes and values especially considering the cognitive and affective dimensions. We verified that the articulation among these dimensions have resulted in a significant work with values, amplifying the probabilities of its construction. Between the aesthetic appreciation of a green area and the proposition of a dilemma, there is an intentionality of the teacher, limits and possibilities of these activities with the senses that are produced, constituting novel ways of speaking about the relationship between society and nature.
\end{abstract}

Keywords: Environmental education. Cognition. Affectivity. Meaning-making.

\footnotetext{
${ }^{1}$ Universidade Estadual Paulista (Unesp), Instituto de Biociências, Departamento de Educação, Rio Claro, SP, Brasil. Orcid: <http://orcid.org/0000-0002-2034-3831>. E-mail: <tha_gasper@yahoo.com.br>.
} 


\section{A Educação Ambiental e o trabalho com valores}

A questão ambiental tem se apresentado como catalisadora de diversos discursos e, do centro dessa problemática nascem caminhos para o enfrentamento de um atual estado de crise, que tem sido adjetivada com termos ambientais, socioambientais, de valores e, até mesmo, da civilização (GONÇALVES, 1998; GRÜN, 1996; GUIMARÃES, 2004; LEFF, 1999; LIMA, 2004;). Um dos caminhos para esse enfrentamento é sinalizado pela contribuição da educação, notadamente a Educação Ambiental (EA) (CARVALHO, 2006). Nesse contexto, passamos a analisar as transformações na relação sociedade-natureza, passando pela revisão de seus pressupostos à construção do novo, não negando conquistas, mas incluindo e abraçando o que de melhor foi produzido, segundo uma perspectiva crítica de educação e de EA, aqui adotadas.

No interior das práticas de EA, Carvalho (2006) destaca três dimensões que devem estar igualmente articuladas e contempladas: conhecimentos, valores (éticos e estéticos) e a participação política do indivíduo. Essas dimensões são inerentes às práticas humanas e devem interagir, constantemente, visando à formação de sujeitos emancipados, críticos, comprometidos com a ação no mundo. Considerando a importância de cada uma das dimensões da EA citadas, bem como a necessidade de compreendê-las em profundidade, destacamos, neste artigo, o trabalho com o conteúdo valorativo da EA. Entendemos que a prática educacional na EA vem se constituindo, também, como uma forma de atentar e refletir sobre os "[...] valores que regem o agir humano e sua relação com a natureza", assim como o "processo de afirmação e legitimação desses valores" (GRÜN, 1996, p. 22).

Sabendo que a relação homem-natureza se constitui, antes de tudo, a partir da forma pela qual tornamos a natureza presente em nossas vidas (BORNHEIM, 1985), compreendemos que a dimensão valorativa, presente no interior da problemática ambiental, é historicamente construída. Essa construção se insere no processo de constituição dos sujeitos, que, por vezes, apropriam-se inconscientemente dos valores construídos na sociedade. Contudo, essa apropriação não é precedida da necessária reflexão, ou de uma autoanálise relativa às motivações que orientam suas escolhas.

Assim, voltando-se para a dimensão valorativa da EA, Bonotto (2003, p. 9) discute a necessidade do trabalho intencional com essa dimensão. Nas propostas educativas, além de se procurar identificar as concepções e valores presentes na atual visão hegemônica de mundo, deve-se apontar para atividades "que possam subsidiar uma nova prática por parte da sociedade". Práticas, estas, que devem ser baseadas tanto na construção de novos valores (BONOTTO, 2008), ou mesmo no resgate daqueles silenciados pelo processo histórico (GRÜN, 1996).

Assumimos a definição de valor a partir de Frondizi (1977) e Payá Sánchez (2008), inferindo que remete à qualidade estrutural da relação sujeito-objeto. Nesse caso, aceitando que a estrutura é mais que uma simples soma das partes, os valores estão no conjunto de todas as relações estabelecidas entre o sujeito e objeto, portanto, ressaltamos que essas relações acompanham o contexto histórico, social e cultural. Dando um caráter relacional ao valor, de tensão entre sujeito e objeto, há uma conciliação possível entre essas partes: não se pode analisar nenhum valor sem a relação do sujeito com o objeto que é valorado. Com isso, sujeito e objeto estão, sempre, em interação (PAYÁ SÁNCHEZ, 2008).

Ao nos referirmos aos valores de interesse ambiental, estamos nos voltando a ideais e princípios que são valorizados na constituição de uma nova visão de mundo, mais adequada do 
Educação ambiental e as dimensões cognitiva e afetiva do trabalho ...

ponto de vista socioambiental. Os valores aqui referidos podem ser identificados nos princípios apresentados no Tratado de Educação Ambiental para Sociedades Sustentáveis e Responsabilidade Global, documento aprovado no Fórum das Organizações Não Governamentais (Fórum das ONGs), que se organizou paralelamente às reuniões oficiais durante a realização da ECO-92. Sendo um documento elaborado pela sociedade civil, possui relevância como representativo dos anseios da sociedade (BONOTTO, 2008).

O trabalho com valores tem, na sala de aula, um ambiente propício para a sua construção, e, embora não se possa garantir sua efetivação em cada aluno, buscar propiciá-lo se faz importante, visto que a sala de aula pode representar um espaço de diálogo, construção de conhecimentos e produção de novos sentidos. Assim, reconhecemos a atuação docente como central nesse processo, pelo fato de os professores serem mediadores de uma possibilidade de transformação, ou, caso contrário, de reprodução do já existente (MANZOCHI; CARVALHO, 2008).

Apontamos, assim, a necessidade de um trabalho explícito, intencional e sistemático com valores, que leve à formação de cidadãos aptos para conviver e fazer escolhas, levando em consideração os níveis pessoal e coletivo de vida. Vislumbramos a formação de sujeitos autônomos e críticos para a ação no mundo, que construam formas de vida mais justas, através de uma razão dialógica: posicionando-se com suas opiniões, reconhecendo-as, a fim de que determinados valores possam ser assumidos por todos (PUIG, 1998a, 1998b).

Para Puig (2004), o trabalho com o conteúdo valorativo pode acontecer em atividades determinadas, por meio de procedimentos específicos, ou em práticas variadas desenvolvidas pelo professor, cujas finalidades expressem valores. O conjunto dessas atividades é considerado pelo autor como um exercício de práticas morais. Tanto o trabalho com atividades determinadas, quanto as práticas diversificadas que expressem valores colaboram para promover a construção da personalidade moral.

Ainda, segundo Puig (1998b), existem diferentes caminhos para o trabalho com os procedimentos específicos: clarificação de valores; exercícios autobiográficos; discussão de dilemas morais; exercícios de role-playing; compreensão crítica, entre outros. A atividade de um dilema, por exemplo, proporciona a elaboração da capacidade de argumentação e julgamentos relativos a temas controversos e complexos. Ao participar dessas atividades, o aluno pode elaborar outras visões a respeito do problema, consultando seus próprios valores e, talvez, modificando-os à medida que se desenvolve cognitivamente.

A partir desse e de outros autores, Bonotto $(2003,2008)$ aponta para três dimensões que devem estar integradas, visando um trabalho significativo: cognitiva, afetiva e da ação. De modo que, por meio da articulação dessas dimensões, a autora explana acerca das possibilidades de promover e/ou ampliar a construção de valores, os quais podem ser apreendidos pelos sujeitos não somente racionalmente, por via cognitiva, mas, também, emocionalmente, por via afetiva, tanto quanto podem ser vivenciados através da ação.

Partindo da proposta de educação em valores de Bonotto (2003, 2008), entrevemos que existem outras dimensões, as quais também podem ser contempladas para a construção de um dado valor. Por exemplo, aquela que diz respeito às emoções, o caminho afetivo. Nessa perspectiva, refletimos sobre a relação entre a dimensão cognitiva e a dimensão afetiva em nossas vidas, já que elas deveriam caminhar juntas e articuladas, procurando superar uma das profundas dicotomias presentes na modernidade - a da razão/emoção. 
Nesse sentido, concordamos com a afirmação de Goergen (2005, p. 1006) de que temos privilegiado, em nossa sociedade, o conceito de educação voltado somente para o aspecto intelectual, "[...] para aquisição de conhecimentos e informações para a interpretação do mundo e o preparo profissional". Entendemos, com isso, que o trabalho com a dimensão afetiva deve ser resgatado e ressignificado em todos os espaços, escolares e não escolares. Inclusive, tangenciando a questão da moralidade ${ }^{2}$ e de construção de nossos valores. A consideração da dimensão afetiva é explicitada nas palavras de Nucci (2003, p. 163), que expressa a ligação entre moralidade e emoção: “[...] nuestros sentimientos no sólo acompañarían a nuestros pensamentos, sino que también desempeñan una función dirigiendo nuestras decisiones”.

A relevância dessa ligação afetivo-intelectiva, muitas vezes, é descartada, ou, na medida do possível, contabilizada, e, desse modo, a moralidade acaba sendo assimilada pela via racional e integrante da via cognitiva. O autor afirma, também, que a integração da afetividade à estrutura cognitiva não deve ser entendida como uma primazia da emoção sobre a razão no funcionamento psicológico, mas, ao contrário, “[...] el afecto no sustituye a la estructura cognitiva (los sentimientos no son conocimiento); en lugar de esto, el afecto es parte y parcela de la inteligencia adaptativa" (NUCCI, 2003, p. 164).

Nucci (2003) ressalta, ainda, a necessidade de reconhecermos que o desenvolvimento da dimensão afetiva nos sujeitos ocorre concomitantemente ao desenvolvimento cognitivo, embora não nos mesmos moldes, mas através das experiências e do ambiente afetivo em que vivem, na convivência frutífera com os próprios sentimentos e emoções.

Segundo essa compreensão, um possível caminho para que trabalhemos com a dimensão afetiva, e que vai ao encontro das propostas acima discutidas, é o da sensibilização e valorização da natureza pela via da apreciação estética. Convencionou-se acreditar que a apreciação estética é experienciada, geralmente, através da arte; mas, estudos apontam (DUARTE JUNIOR, 2006; HERMANN, 2005) que a apreciação atenta da realidade, a partir de uma perspectiva que admita a estetização da vida cotidiana, pode conduzir à sensibilização, à condição de estesia, ou seja, de estar sensível a algo.

Vale lembrar que, também em imagens, poemas, músicas e textos essa apreensão permite ir além da dimensão cognitiva, interpretada - ou até mesmo reduzida - pelo conhecimento científico (MARIN, 2006). Autores que vislumbram esse caminho enfatizam que a apreciação estética redimensiona o lugar e o papel do homem no mundo, pois a arte "[...] se refere à capacidade humana de transcender o olhar imediatista sobre as coisas que compõem o mundo" (MARIN, 2006, p. 279). Salientamos, ainda, as afirmações de Bonotto (2008) sobre a apreciação estética, como um caminho propício à EA, demonstrando que pode trazer contribuições importantes ao trabalho com valores, conforme evidenciado, também, em Bonotto e Rodrigues (2010).

Depreendemos, em acordo com nossa exposição, que essa outra forma de apreensão do mundo, a qual direciona a dimensão afetiva articulada ao trabalho com a dimensão cognitiva, pode fornecer subsídios à construção de valores que orientem uma outra relação com a

\footnotetext{
${ }^{2}$ Segundo Araújo (2001), todos nós possuímos nosso sistema de valores, conjunto constituído tanto por valores que são morais como por outros que não o são. O que faz com que um valor seja considerado moral é seu vínculo com conteúdos de natureza moral, esse conteúdo é ditado pelas diferentes sociedades ao longo do tempo, constituindo-se a moral, um conjunto de regras de conduta que orientam o comportamento das pessoas.
} 
Educação ambiental e as dimensões cognitiva e afetiva do trabalho ...

natureza. Além disso, tal articulação afetivo-cognitiva pode nos encaminhar à ação consciente, intencional, visando à construção de relações que privilegiem a alteridade e o outro, dando voz ao que foi objetificado e construindo, assim, novos sentidos para a relação sociedade-natureza.

Para a produção desses outros sentidos, atentamos ao papel que o diálogo e o outro possuem em nossas relações, especialmente aquelas mediadas pela linguagem. Essas reflexões estão presentes no aporte teórico sobre a filosofia da linguagem em Bakhtin, bem como no entendimento de Vygotsky a respeito do caráter mediador do professor na aprendizagem. Assim, apontamos, a seguir, esses autores como referenciais que nos auxiliam na discussão de caminhos que possam subsidiar uma prática voltada à EA e o trabalho com valores.

\section{De Vygotsky a Bakhtin: o diálogo, o outro e a produção sentidos}

Compreendemos o processo de aprendizagem através da teoria de Vygotsky, que ressalta a necessidade do envolvimento ativo do aluno nos diálogos em classe, onde o conteúdo, para ser internalizado, deve, antes, ter tido algum significado na experiência pessoal do sujeito, através de suas interações sociais (PINO, 1993). Smolka (1993) afirma que, na perspectiva de Vygotsky, os processos verbais são, inicialmente, do outro e, depois, próprios do sujeito, sendo estruturadores da atividade mental do indivíduo.

Com isso, entendemos ser essencial dar voz tanto a diálogos entre professor e alunos, e, ainda, considerando esses últimos, ao aluno, para que ele participe e se posicione em questões valorativas, possibilitando que se envolva na construção tanto de conceitos como de valores, de modo que adquiram significado em sua vida. A interface entre o social e o individual demarca, para Vygotsky, uma unidade de análise para o estudo do funcionamento mental: os significados das palavras (SMOLKA,1993).

Atentos à compreensão dessa construção de significados, Mortimer e Scott (2002) analisam episódios de ensino, em sala de aula, como contextos propícios, tendo a figura do professor como mediadora do processo. Essa mediação está intrinsecamente ligada ao uso da linguagem, instrumento fundamental para a constituição do homem e a construção de conceitos (AGUIAR; OZELLA, 2002).

Nesse sentido, a filosofia da linguagem trazida por Bakhtin (2006) nos possibilita a compreensão dos enunciados através de uma perspectiva da natureza constitutivamente dialógica da linguagem. Segundo Brait (2005, p. 94) os enunciados são entendidos como indissoluvelmente ligados "[...] às condições de comunicação, que, por sua vez, estão sempre ligadas às estruturas sociais", e referem-se a quaisquer signos ou discurso, enunciados em um contexto históricosocial, que trazem consigo um sentido completo, e não somente o significado da palavra, mas intenções, visões de mundo, de seu horizonte conceitual (BRAIT; MELO, 2005).

Da teoria bakhtiniana, compreendemos que nos diálogos expressam-se enunciados entre os interlocutores, formando um elo da cadeia da comunicação, pois cada diálogo faz parte da compreensão ativa do sujeito em relação ao outro, um ato único e responsivo em resposta ao mundo. Assim considerado, inferimos que nos enunciados de professores e de seus alunos são trazidas visões de mundo, ou ideologias. Nesses enunciados há a expressão de uma ideologia do cotidiano que, muitas vezes, representa visões de mundo não oficiais frente ao mundo da cultura já instituído, constituindo um lugar de expressão das diferentes vozes dos sujeitos, de criação e possibilidade de construção do novo (BAKHTIN, 2006). 
Desse modo, a partir de Smolka (1993) adotamos como objeto de estudo o diálogo por meio das interações verbais em sala de aula, considerando que esse foco de análise aproxima-se do que apontamos como desejável à construção de valores. Smolka (1993, p. 10) avalia o discurso verbal como importante instrumento para a análise das práticas docentes e assume que "[...] a significação se produz na dinâmica das interações verbais". A autora privilegia o que chama de processos de enunciação como lugar de produção de conhecimento e de sentidos, elegendo o movimento discursivo como objeto teórico-metodológico. Na perspectiva de Bakhtin, a autora entende que, nessa análise, possibilita-se considerar aspectos não só da estrutura cognitiva dos sujeitos, mas do jogo de interesses sociais, por meio dos signos ideológicos em seus enunciados, os quais contêm sua visão de mundo dentro do contexto histórico-social em que se situam. E, nessa visão de mundo, subjazem os valores, foco de nosso interesse.

Analisar os movimentos discursivos pode, ainda, nos mostrar o espaço de trocas entre diferentes, bem como o espaço de criação e construção de outras possíveis visões de mundo, através da ideologia do cotidiano (BAKHTIN, 2006). Fato que nos aproxima do trabalho com a temática ambiental e seu conteúdo valorativo, pois está propondo-nos reflexões, resgate ou construção de novos valores em favor de uma transformação da relação entre sociedade e natureza. Abrange, também, a construção de novas visões de mundo, ou ideologias, ou ainda, o reforço a ideologias do cotidiano que representem visões mais apropriadas do ponto de vista socioambiental. Desse modo, analisar os diálogos e a produção de sentidos presentes no trabalho com valores, em diferentes dimensões, pode colaborar no entendimento dessa construção, principalmente, procurando discutir as contribuições trazidas pelas vias cognitiva e afetiva na construção de valores.

Nesse contexto, partindo de um trabalho de pesquisa de mestrado já finalizado, objetivamos apresentar e analisar os sentidos construídos nas práticas relativas à temática ambiental e seu conteúdo valorativo em dois episódios de ensino ${ }^{3}$. Ambos são referentes ao trabalho de uma professora de ensino fundamental, que se encontrava no contexto de um programa de formação continuada. Um deles trata do trabalho com valores mais ligado à dimensão afetiva e à apreciação estética da natureza (Episódio 1). O outro evidencia o trabalho com valores mais ligado à dimensão cognitiva e a um procedimento específico para seu trabalho, a discussão de um dilema (Episódio 2).

\section{Caminhos de Pesquisa}

A pesquisa foi desenvolvida sob uma abordagem qualitativa (LÜDKE; ANDRÉ, 1986). A professora em questão participava de um projeto de extensão de uma universidade, a qual promovia, naquele período, o programa de formação continuada denominado "Educação Ambiental e o trabalho com valores", oferecido a professores da Rede Estadual de Ensino Fundamental em uma cidade no interior do Estado de São Paulo, entre abril a dezembro de 2010. O programa teve como proposta final a construção e implementação de planos de aula a respeito

\footnotetext{
${ }^{3}$ Por questões de delimitação de espaço nos restringimos, neste trabalho, à análise de dois episódios de ensino.
} 
Educação ambiental e as dimensões cognitiva e afetiva do trabalho ...

dessa temática, no qual foram elaborados diferentes projetos de natureza interdisciplinar, visto que a proposta visava articular professores de diferentes disciplinas.

O processo foi acompanhado pela pesquisadora através da observação direta e videogravações das aulas que, posteriormente, foram transcritas; bem como, da elaboração de um diário de campo. O plano de aula elaborado pela professora também fez parte do material analisado, na busca por subsídios para a compreensão do processo, desde seu planejamento até a implementação (ALVES-MAZZOTTI; GEWANDSZNAJDER, 2001).

A professora lecionava a disciplina de Língua Portuguesa, para uma turma de $6^{a}$ sé$\mathrm{rie} / 7^{\circ}$ ano. Os referenciais estudados no programa de extensão fomentaram um plano de ensino que foi desenvolvido ao longo de doze aulas. O plano "FEENA: Patrimônio Histórico, Cultural e Paisagístico de Rio Claro" apresentou os seguintes objetivos: compreender a importância da Floresta Estadual Edmundo Navarro de Andrade (FEENA) 4 para a cidade de Rio Claro, em seus aspectos ambiental, cultural e histórico; valorizar o potencial paisagístico, a partir do resgate do valor histórico e construir novos padrões de relacionamento com o meio natural.

Para a análise da prática da professora, primeiramente, realizamos um mapa de eventos de todas as suas aulas, o qual permite "[...] examinar o desenrolar das interações discursivas entre professor e alunos como também relacionar formas de explicar associadas às atividades realizadas" (MARTINS; NASCIMENTO; ABREU, 2004, p. 99). Segundo Martins (2006), os eventos não emergem naturalmente, e sua delimitação é um ato interpretativo, que se utiliza de critérios como o referencial teórico e os objetivos da pesquisa. A partir do mapa de eventos, podemos traçar um plano inicial da prática docente, suas estratégias e conteúdos, bem como os momentos mais marcantes do trabalho, configurando-se uma base para uma análise posterior mais detalhada. Após construirmos os mapas de eventos foram, portanto, selecionados os episódios de ensino com momentos mais significativos para o trabalho com a temática ambiental e seu conteúdo valorativo.

Adotamos a definição de episódios de ensino como recortes de sequências discursivas relacionadas ao foco central da investigação (GÓES, 2000; SANTOS; MORTIMER, 2009). Em nosso caso, as situações significativas remetem aos momentos em que o professor discute, explicitamente, a temática ambiental e os valores, nos quais há um trabalho diferenciado do professor, ou que apontam para uma riqueza na produção de sentidos. Ressaltamos que o contexto responsável por situações significativas pode ser definido como um episódio de construção de significados em sala de aula (MORTIMER, 2000). Aqui, os recortes correspondem a sequências de interações discursivas entre professor e alunos durante as aulas gravadas.

A produção de sentidos foi empreendida a partir do encontro entre a pesquisadora e os dados produzidos na pesquisa, de acordo com Martins (2006, p. 300). A autora afirma que a pesquisa é, ela própria, um processo de interação discursiva e construção de sentidos “pelo qual os dados são construídos a partir de registros de observação". Para isso, verificamos que essa compreensão envolve todo o processo, desde a preparação dos planos de aula até a observação das aulas propriamente ditas, além do contexto mais amplo/remoto no qual essa atividade se insere, como aponta Martins (2006, p. 309):

\footnotetext{
${ }^{4}$ A FEENA é uma Unidade de Conservação (UC) do município de Rio Claro, SP, e recebe visitantes da cidade e região para atividades de passeio e visitas monitoradas.
} 
Os sentidos que construímos para as interações emergem [...] em três níveis: (i) dos episódios (eventos específicos realizados por interações localizadas);

(ii) de aspectos do contexto empírico imediato (padrões e sequências observadas em contextos de interação estendidos, por exemplo, a aula); (iii) de aspectos mais globais do contexto empírico remoto (por exemplo, o discurso das recomendações curriculares).

Iniciamos uma contextualização desses episódios já nos mapas de eventos, onde detalhamos e analisamos todo o trabalho do professor. Essa contextualização foi seguida, em níveis mais específicos, na própria descrição do acontecimento do episódio de ensino durante sua análise. A análise dos episódios de ensino foi baseada em Smolka (1993), que se apropria do movimento discursivo entre os falantes para realizar asserções. A autora traz alguns apontamentos que orientaram nossa perspectiva de pesquisa:

[...] procurar identificar diferentes vozes que entram em contato no processo de elaboração conjunta do conhecimento. Como pensar a construção de conhecimento na dinâmica interativa, discursiva? Quem fala? De que lugares? Que vozes podem ser ouvidas? Interessa-nos não apenas apontar ou descrever estas vozes, mas analisá-las no contexto de sua produção (SMOLKA, 1993, p. 6).

A análise proposta por Smolka permite compreender as diferentes vozes e visões de mundo presentes nos discursos de professores e alunos, bem como a intencionalidade do docente ao conduzir o assunto. Por isso, Smolka (1993, p. 7) aponta que, nos movimentos discursivos é possível “[...] identificar marcas de uma prática pedagógica que, no jogo instrução/ construção, privilegia a interação e possibilita a explicitação de formas coletivas de construção do conhecimento".

Entendemos que a análise deva ser a mais detalhada e aprofundada possível, envolvendo não só o conteúdo verbal dos signos, mas, também, seu conteúdo extraverbal (BAKHTIN, 2006). Concordamos com Cereja (2005) ao afirmar que o sentido do enunciado vai além dos elementos linguísticos, já que compreende, também, as escolhas sintáticas e fonéticas, entonação e, além disso, a identidade dos interlocutores, a finalidade da enunciação, o momento histórico, fundamentais para a compreensão dos sentidos. Assim considerado, a partir das videogravações das práticas docentes e de uma contextualização da produção de suas práticas, procuramos abranger, nesta análise, na medida do possível, as dimensões extraverbais do discurso. 


\section{Os Episódios de Ensino}

Neste tópico trazemos a análise e reflexões a respeito de cada episódio de ensino, incluindo sua duração em tempo e turnos de fala 5 .

\section{Episódio 1 - 26/10/2010, Duração 2min22seg, Turnos 471-484}

O Episódio 1 ocorreu durante a visita à FEENA, quando os alunos e a professora estavam em uma das trilhas da UC, guiados por duas monitoras, as quais realizaram com os visitantes um roteiro anteriormente estabelecido, que incluía a visita ao museu local e a realização da referida trilha. As atividades foram acompanhadas de informações históricas, culturais e biológicas. Naquela ocasião, a professora encontrava-se junto aos alunos, acompanhando-os na explanação das monitoras, e colocava-se, também, como participante de um momento de apreciação da paisagem.

Antes da visita à FEENA, a professora fizera um pedido aos alunos: que realizassem um registro fotográfico de uma imagem que lhes chamasse a atenção ou thes despertasse algum sentimento. O registro da imagem poderia ser feito em qualquer momento que os alunos sentissem vontade. Por isso, a professora caminhava junto aos alunos com a câmera fotográfica, e, quando eles queriam fotografar, ela lhes oferecia a câmera para que eles próprios registrassem a imagem. Assim, nesse episódio havia um grupo de aproximadamente seis alunos junto à professora, os quais estavam apreciando a paisagem e procurando detalhes que lhes chamassem a atenção para fazerem o registro, enquanto outros alunos caminhavam mais à frente da trilha, junto às monitoras.

Assim se inicia o Episódio 1:

471. Profa.: Olha que lindo aqui! [Algumas falas inaudíveis]

472. A.: Professora, vai cair, vai cair! [apontando para uma árvore]

473. Profa.: Uma está segurando a outra.

474. S.: Elas estão se ajudando! [...]

475. S.: Eu acho que por aqui é tão perigoso!

476. Profa.: Não é, não...

477. S.: Tem uma semente, tipo um fruto grande, que fica caindo.

478. Profa.: Será que é do primeiro?

479. S.: Ai eu andei numa trilha, eu andei um pedacinho e aí ficava caindo.

480. Profa.: É a fruta dela, né? O fruto.

481. S.: Mas os frutos caem na cabeça, né?

\footnotetext{
${ }^{5}$ Os episódios trazidos contarão com as seguintes indicações: A: Aluno não identificado através das imagens do vídeo; A (número) ou Letra (referente à inicial do nome): Aluno identificado que recebe a mesma numeração pelo menos na mesma aula (A1, A2,...) ou aluno identificado pelo nome $(A, G, \ldots)$, que recebe a letra de sua inicial como identificação; AA: Quando houver a fala conjunta audível de mais de um aluno; [xxx]: Quando alguma fala é inaudível devido a distância do emissor à fonte de recepção; [...]: Contém um comentário do transcritor, com esclarecimentos sobre o contexto da aula. Os números referem-se aos turnos de fala, que são a alternância dos sujeitos falantes nos diálogos desenvolvidos na sala de aula adaptadas de Santos (2002).
} 
482. Profa.: É mas... épor isso que você tem que andar atento a todos os seus sentidos aí. Audição, visão... tá?

483. S.: Tem que ter olho em volta da cabeça inteira.

484. Profa.: [respira profundamente] Gente, que delícia que é respirar esse ar!

O Episódio 1 apresenta, com clareza, um momento de apreciação estética da natureza, em que se privilegia a dimensão afetiva no trabalho com valores (BONOTTO, 2003, 2008). Vemos que, por ocasião da visita e na trilha que realizavam, a professora, encontrando-se fora da sala de aula, estava em um momento de maior abertura à produção de sentidos, os quais não precisariam, necessariamente, estar direcionados aos conhecimentos sobre a floresta - característica que comumente encontramos em sala de aula. Naquele momento, importavam a vivência e a experiência com a própria floresta. Assim, encontrando-se em maior liberdade, no Episódio 1 a professora traz à baila, na conversa, sentidos ligados à dimensão afetiva do trabalho com valores e, ainda, relaciona-se afetivamente com os alunos, preocupando-se com eles. Ao final, correspondendo ao clima afetivo ali instaurado, verbalizou o quão importante é estarmos atentos ao nosso próprio corpo e sentidos ao andarmos na floresta.

$\mathrm{Na}$ análise dos movimentos discursivos, observamos que o Episódio 1 se inicia com um enunciado da professora, que expressou, em tom apreciativo, a beleza do local que estava sendo visitado (Turno 471 - "Olha que lindo aqui!'), trata-se de um enunciado com forte entonação expressiva, que produz o tom e os sentidos desse episódio. Após esse enunciado, há um tempo de silêncio e alguns alunos participam do diálogo. Um deles dá continuidade ao caráter de apreciação da natureza e, observando a situação singular de duas árvores com os galhos entrelaçados, aponta para elas e comenta, assustado: "Professora, vai cair, vai cair!" (Turno 472). A professora, porém, tranquiliza-o, e mantendo o clima de apreciação diz: "Uma está segurando a outra" (Turno 473). Naquele momento, dando continuidade aos sentidos que estavam sendo produzidos, outro aluno se apropria do enunciado da professora e complementa-o: "Elas estão se ajudando!" (Turno 474). A professora não realiza nenhum comentário ou avaliação desse enunciado do aluno, deixando aberta a produção de sentidos e a participação de outros alunos que quisessem contribuir nos diálogos.

Alguns passos adiante, o mesmo aluno comentou com a professora que considerava perigoso andar naquele local da trilha na floresta (Turno 475). Ele justificou seu medo ao dizer à professora que, uma vez, caminhava em uma trilha e algo caiu de cima das árvores (Turnos $477,479,481)$. A professora, então, procurou desconstruir a ideia exposta em seus enunciados, discordando da preocupação do aluno (Turno 476 - 'Não é, não...') e apontando a ele uma solução para que não tivesse medo de caminhar na trilha (Turno 482 - "É mas... é por isso que você tem que andar atento a todos os seus sentidos aí. Audição, visão... tá?’”. Assim, concordando com o sentido atribuído pela professora, o aluno enunciou, em tom divertido: "Tem que ter olho em volta da cabeça inteira" (Turno 483). Os dois interlocutores riram, tornando mais evidente a abertura e a afetividade presentes nesses movimentos discursivos.

Tais diálogos, além de indicarem a atenção voltada para apreciar o local e a experiência de caminhar por ele, em conformidade com as considerações de Marin (2006) e Rodrigues e Bonotto (2010), deixam transparecer as emoções que emergem, pois tratam da experiência do corpo em um local diferenciado do meio urbano, onde há muitas formas de vida não costumeiras no meio urbano se manifestando. $\mathrm{O}$ fato de o aluno considerar tal local perigoso vincula- 
se, possivelmente, ao fato de que aquela experiência era rara para ele e diferente de sua vida cotidiana, que, provavelmente, ocorrera, em sua maior parte, na zona urbana, onde há menor diversidade de animais, plantas e elementos naturais, sendo predominante uma construção toda voltada aos interesses humanos.

O Episódio 1, a nosso ver, evidencia uma possibilidade promissora de articulação da dimensão afetiva e de sensibilização com as outras dimensões (cognitiva e ação) no trabalho educativo de construção de valores, o que, de acordo com Bonotto $(2003,2008)$ amplia esse trabalho, pois apenas o conhecimento das características do local não traria esse aspecto que somente a vivência pode oferecer. Trata-se de uma experiência que faz parte do envolvimento ativo do sujeito e acontece individualmente. Podemos destacar que, no citado episódio, a aproximação entre o aluno e a professora nos traduziu uma experiência voltada para a apreciação estética, aprendizado e até de diversão para ele.

Mais alguns metros e a professora, ainda caminhando junto com um grupo de alunos, respirou profundamente e exclamou: "Gente, que delícia que é respirar esse ar!" (Turno 484). O tom apreciativo produzido nos sentidos desse enunciado é o mesmo evidenciado no início desse Episódio 1, no Turno 471. Observamos, novamente, a importância que a professora estava atribuindo ao local, e o quanto suas falas, demonstrando aspectos pessoais, assumiam uma posição valorativa. Ao mesmo tempo, podemos visualizar que ela se posicionava também como professora, influenciando-os para a apreciação, de certo modo "ensinando-os" a contemplarem o local.

Os sentidos produzidos no Episódio 1 remetem, portanto, à experiência com o local e suas particularidades para a construção da valorização da FEENA, a qual foi experienciada, naquele momento, mais pelos sentidos do que pelas ideias. Observamos que tal ocasião proporcionou que a professora reforçasse a dimensão afetiva em seus enunciados e ações, que, conforme Nucci (2003), se faz necessária para acompanhar o trabalho cognitivo.

\section{Episódio 2 - 03/11/2010, Duração 2min36seg, Turnos 132-155}

O Episódio 2 narra o término da discussão de um dilema, baseado na proposta de Puig (1998b), como um procedimento específico para o trabalho com valores. Essa atividade foi realizada na aula seguinte à visita na FEENA, quando os alunos pareciam estar muito animados com o que aprenderam e vivenciaram na floresta. As carteiras da sala estavam dispostas no formato de um semicírculo e o clima, na aula, entre professora e alunos era amistoso, assim como já evidenciado anteriormente. O dilema proposto foi o seguinte: Um grande problema da Floresta (FEENA) como uma Unidade de Conservação é a falta de verbas para a manutenção e a revitalização. Se um parque de diversão quisesse se instalar no espaço da Floresta, ocupando grande parte dela e afirmando que forneceria a verba necessária para os cuidados com o resto, que sobrou da Floresta, você abriria mão da Unidade de Conservação? (Turnos 24 e 26).

Após a leitura da questão, a professora pediu para que os alunos a respondessem e se posicionassem, argumentando sobre a resposta escolhida. Frisou que esperava que eles escrevessem o que realmente gostariam - que não haveria resposta certa ou errada. Assim, a professora determinou um tempo aos alunos, para que discutissem a questão em duplas, mas indicando que a resposta deveria ser elaborada individualmente e, depois, apresentada aos colegas. No momento em que se iniciou a leitura das respostas, constatou-se que todos os alunos se posicionaram contra a construção do parque de diversões, sempre apontando argumentos que destacavam a importância da floresta: que o parque iria destruí-la; que ela é um patrimônio do município; que 
prejudicaria outros animais que nela vivem, entre outros aspectos. A professora foi ouvindo os argumentos e não se posicionou em nenhum momento, porém, quase no término da atividade, uma aluna que já havia respondido ser contra o parque pelos mesmos motivos anteriores, teceu um comentário que deu início ao Episódio 2:

132. B.: Ah, você acha que ninguém aqui ia querer o parque?

133. Profa.: É, eu estou aqui me contendo pro final!

134. B.: Eu ia, mas [\#\#\#].

135. L.: Professora, é mentira, porque en queria...

136. B.: Verdade, sora, agora en vou colocar minha reposta sincera aí.

137. Profa.: Mas, escuta, mas en pedi que vocês colocassem a opinião de vocês, que não tem certo ou errado.

138. L.: Ah, então eu vou colocar sim.

139. Profa.: Você tem que colocar o que você... L., você tem que pensar no que você realmente acredita que seja melhor, entendeu? Diante de tudo o que você conhece, do que vocêpensa, do que você...

140. L.: $O$ melhor,

141. B.: O melhor é a Floresta né, mas...

142. Profa.: Então, mas o que pesa mais e por quê? É isso que en quero saber.

143. A2.: Não, porque acabaria com a maior parte da Floresta e não teria mais aquela parte bonita

144. Profa.: E a M.?

145. M.: Não, porque a Floresta, ela tem uma paisagem bonita, e prejudicaria os animais e estragaria essa bonita floresta que nós temos.

146. Profa.: Tá. Pessoal, então é o que que ia falar. Eu me surpreendi com tantos "Não"; mas eu deixei bem claro no começo que vocês tinham que se posicionar contra ou a favor e dar os motivos. De repente, você colocaria um "sim", e argumentaria o porquê desse sim. Não é? Então não é pra, tinha que colocar o "não"; não! Tinha que colocar realmente o que você pensa diante disso daqui, dessa pergunta, ok?

147. K.: Mas eu pensei, por causa que tem vários lugar pra construir o parque e vai construir bem no lugar da Floresta?

148. B.: É, verdade, eu pensei nessa mesma coisa.

149. Profa.: Que poderia ser um outro local.

150. Ke.: [\#\#\#]

151. Profa.: É. A Ke. está falando que tem vários parques, em vários lugares, por que que tinha que destruir aqui pra construir um outro?

152. T.: Isso que en quis dizer.

153. I.: Isso, tem o Hopi Hari, tem um Playcenter...

154. B.: [\#\#\#]

155. Profa.: Sim, pensando no futuro. Então tem vários lugares. Então gente, nós vamos encerrando por aqui.

O Episódio 2 aponta para uma das dificuldades ao trabalho com procedimentos específicos para a construção de valores, conforme explanado por Bonotto (2003). Tal dificuldade 
é exemplificada na fala inicial da aluna insatisfeita com a opinião que toda a turma manifestou em seus argumentos, pois para ela os alunos não estavam dizendo realmente o que pensavam. Avaliando o fato, a professora relembrou que não havia resposta certa ou errada. Porém, o que provavelmente ocorreu foi que, no "calor" das reflexões sobre a FEENA, ou no intuito de agradar à professora com suas opiniões, os alunos, provavelmente, não teriam refletido sobre o dilema, ou, se o fizeram, negaram suas preferências para responder o que seria "a resposta correta". Nesse procedimento, segundo Puig (1998a), sentir-se livre e acolhido é essencial para posicionar-se, além de saber explicar o porquê da escolha de uma determinada posição. Tal passo é muito importante para o desenvolvimento da reflexão e do juízo moral, que proporcionam a capacidade de construir juízos cada vez mais elaborados e desenvolver a autonomia moral.

Assim, a professora procurou mostrar aos alunos a importância de responderem aquilo que realmente consideravam o correto a ser feito, reconhecendo que seria desse modo que seus verdadeiros valores e posicionamentos seriam apresentados. Somente a partir disso, os alunos encontraram novos argumentos para o dilema, indicando que a construção do parque poderia ser em outro local, sem que houvesse a destruição de parte da floresta. Essa alternativa evidencia uma construção de justificativas em um nível mais complexo. No caso, ao mesmo tempo em que os alunos não abrem mão da floresta, e, portanto, o valor da manutenção da floresta articula-se à construção do parque, concordam que a construção deste não precisaria ser abandonada, podendo ocorrer em outro local.

Analisando a produção de sentidos ao longo do Episódio 2, atentamos que o início dos diálogos se encontra no enunciado de uma aluna, que, decidindo expor sua própria opinião, questionou a professora sobre se todos os alunos realmente pensavam tal como estavam dizendo nos argumentos antes apresentados: "Ah, você acha que ninguém aqui ia querer o parque?" (Turno 132). Com esse enunciado a aluna antevê, sem saber, um sentido que a professora gostaria de enunciar, mas que ainda não o fizera, pois aguardava outros posicionamentos dos alunos (Turno 133 "É, en estou aqui me contendo pro final!"), o que nos aponta para o clima de abertura que a professora ainda desejava proporcionar aos alunos na atividade do dilema.

Quando a aluna se posicionou positivamente quanto à construção do parque (Turno 134), foi seguida por sua colega ao lado (Turno 135), e, então, elas decidiram assumir sua posição, dizendo que, agora, colocariam sua resposta sincera no papel (Turno 136). Com isso, nesses movimentos dos diálogos, a professora decidiu posicionar-se e enunciar o que ela havia pedido na atividade, evidenciando que era importante colocar a própria opinião, sem recear a mesma fosse avaliada como certa ou errada pela professora, como vemos nos trechos: "eu pedi que vocês colocassem a opinião de vocês" e "não tem certo ou errado" (Turno 137). Esse posicionamento é reforçado no Turno 139, no qual a professora, incentivando a aluna a colocar sua opinião, diz que ela deve se basear "no que você realmente acredita, que seja melhor" e "diante de tudo o que você conhece, do que vocêpensa" (Turnos 140 e 141). As alunas parecem compreender o que a professora apontou, e enunciaram ponderando que, embora a floresta fosse melhor, o parque também seria interessante.

São enunciados que produzem sentidos que privilegiam a construção da autonomia dos alunos, valorizando a opinião deles, bem como a sustentação da mesma através de sua argumentação, de acordo com as orientações de Puig (1998a). Observamos que a professora tem clara consciência da importância de os alunos se expressarem de maneira autônoma, segundo a própria opinião, pois nela se encontrariam os valores, e, então, estes poderiam ser trabalhados através de um raciocínio lógico e reflexivo, no contexto do grupo. 
Continuando a análise, os diálogos encaminham-se para a construção de outros sentidos, vinculados, ainda, à não construção do parque, voltando à ideia inicial defendida pelos alunos. Nos Turnos 143 ("Não, porque acabaria com a maior parte da Floresta e não teria mais aquela parte bonita") e 145 ("Não, porque a Floresta, ela tem uma paisagem bonita, e prejudicaria os animais e estragaria essa bonita floresta que nós temos"). Observamos que os sentidos que emergem estão ligados à manutenção da FEENA, por sua beleza e pela importância para os animais. Essas alunas foram as duas últimas da turma a exprimirem sua opinião.

No momento de finalização da atividade, a professora posicionou-se, mostrando aos alunos que, talvez, tenham pensado apenas em um dos lados, ou não tenham argumentado sobre o que realmente gostariam (Turno 146). Assim, demonstrou aos alunos sua surpresa com as respostas. Salientamos que ela deixou clara a importância do posicionamento e, nesse enunciado, são produzidos sentidos semelhantes àqueles enunciados nos Turnos 137 e 139.

A partir desse direcionamento dado pela professora, uma aluna, com seu enunciado, produziu novos sentidos nesse diálogo, os quais, apontando para a construção de um argumento mais reflexivo acerca da possibilidade de construção do parque de diversões, conciliando a construção com a manutenção da floresta. No Turno 147, ela argumentou sobre porque o parque teria que ser construído "bem no lugar da floresta", pois há outros lugares para sua construção. A aluna que argumentara ser a favor do parque, concordou com sua colega (Turno 149), apropriandose do sentido desse enunciado. A professora, compreendendo a importância dos enunciados, repetiu-os para toda a turma, utilizando novamente os signos "vários lugares" para que seu sentido fosse destacado (Turno 151). Outros alunos concordaram com a professora, exemplificando essas possibilidades e citando alguns parques conhecidos por eles (Turnos 152 e 153).

Com isso a professora finaliza os diálogos e conclui a atividade do dilema, direcionando-o, ao final ${ }^{6}$, para uma solução considerada mais ponderada, em que a floresta é mantida, mas sem abrir mão do parque de diversões. A professora, com isso, deixou um sentido final, mais diretivo, em termos de qual seria a prática mais correta do ponto de vista ambiental com relação à FEENA. Até que ponto encerrou esse procedimento, conduzindo-o, de forma mais adequada, segundo as orientações gerais para essa modalidade de trabalho, permanece uma questão em aberto.

Reconhecemos que não é uma decisão tão simples de ser tomada e que, possivelmente, não haja uma regra geral a ser seguida, pois o trabalho dependerá do contexto em que está inserido, levando-se em conta a faixa etária dos alunos e o contexto cultural em que se inserem. No caso aqui narrado, os sentidos foram construídos a partir do apontamento de uma aluna que sentiu essa abertura para posicionar-se, mas, também, a partir da posterior orientação da professora mediante uma intervenção mais diretiva, quando os alunos puderam refletir melhor e apropriaram-se dos sentidos expressos pela aluna que iniciara os diálogos.

\footnotetext{
${ }^{6}$ Para Puig (1998b), ao final da discussão de um dilema moral o professor não se posiciona ou dá a palavra final, devido a essas discussões serem situações que não oferecem uma solução única ou totalmente clara, que levem o aluno a refletir, argumentar e justificar, racionalmente, a alternativa que lhe pareça mais justa.
} 
Educação ambiental e as dimensões cognitiva e afetiva do trabalho ...

\section{Considerações Finais}

Após esse trabalho de busca de compreensão dos diálogos e dos sentidos produzidos nas experiências investigadas, podemos apontar algumas características sobre o trabalho com valores na escola, mediante o alcance das diferentes dimensões que ele abrange. A relação complementar entre as dimensões afetiva e cognitiva do trabalho com valores aqui se expressa com clareza e demonstra diferentes oportunidades para a prática educativa, onde cada um deles evidencia a complexidade do trabalho com o tema, mas, também, grandes oportunidades de produção de novos sentidos.

Sugerimos que fica claro que o clima estabelecido entre professora e alunos é essencial para que haja o desenvolvimento de um trabalho efetivo com qualquer uma das dimensões, porém, a nosso ver, faz-se necessária uma sensibilidade mais apurada do professor, quanto às palavras e ações, quando se trabalha com essas dimensões.

A experiência estética na visita à floresta, no Episódio 1, nos remeteu a um momento intenso de emoções, seja dos alunos, com suas expectativas, como também da própria professora. Todos se mostraram aprendizes em meio ao ambiente natural. Assim, também podemos entender que a construção de valores é coletiva, pois, nesse episódio específico observamos que todos se inseriram no processo e nas relações, professor e alunos juntos, produzindo o novo.

Quanto ao Episódio 2, pontuamos que valores também podem ser construídos a partir da dimensão cognitiva; vimos que os sentidos produzidos a partir do trabalho com um procedimento específico, um dilema, podem contribuir na elaboração de argumentos, e, por conseguinte, na construção de valores, além de tornar possível a revisão de um valor já discutido, assim como a elaboração de novas escolhas. Os assuntos associados à temática ambiental são complexos e envolvem controvérsias, que, de acordo com a condução das situações, podem favorecer o desenvolvimento da capacidade de raciocínio crítico e da argumentação condizente com esse raciocínio. Portanto, proporcionar esse momento aos alunos, mesmo que a partir de uma situação hipotética, pode propiciar que repensem os próprios valores, abrindo a possibilidade de construírem novos, assentados na reflexão subjacente.

É necessário salientar nosso entendimento de que a construção de valores foi propiciada em ambos os episódios, ampliando-se a possibilidade de sua apropriação por parte dos alunos. No entanto, não há garantias, sendo que esse processo somente poderá ser percebido a longo prazo, a partir de outras situações. Além disso, reconhecemos que os sentidos produzidos na intencionalidade da docente ligam-se ao contexto de formação continuada da qual participava (MARTINS, 2006), o que também não implica que tenham sido incorporados definitivamente em suas práticas e prossigam em seu cotidiano. Retomando o que aponta Frondizi (1977), os valores se constroem no conjunto das relações estabelecidas entre o sujeito e objeto, que se relacionam, sempre, ao contexto em que ocorrem essas relações.

Também, destacamos a importância do papel do professor em suas palavras e ações frente aos alunos: ele é o orquestrador das diferentes vozes presentes no grupo. O posicionamento frente às questões que envolvem seus conhecimentos e à relação com os alunos são construções essenciais em todo o processo de ensino e trabalho com valores. As práticas desenvolvidas pela professora, aqui investigadas, a nosso ver, constituíram práticas morais (PUIG, 2004), pois todo o seu processo foi elaborado para tal finalidade, permitindo expressar valores. 
Concluindo, consideramos ser essencial um olhar atento à prática docente, com o desejo de entendimento da mesma, e reconhecendo que é permeada por muitas histórias, inclusas aquelas que se inserem na própria formação. Como apontado no início deste artigo, é fundamental a reflexão, seja no âmbito da formação inicial ou continuada, bem como a elaboração de propostas de ensino, tornando os professores também autores da própria docência.

Ainda, desejamos ressaltar que os sentidos produzidos nesses episódios de ensino, além de se configurarem como momentos importantes para a análise do trabalho com valores, se inserem, principalmente, na produção do novo, que pode contribuir com a identificação de ideologias presentes no cotidiano, emergindo daí novos discursos que podem colaborar para trazer uma transformação do quadro de crise instaurado, bem como na produção de uma outra relação entre sociedade e natureza.

\section{Agradecimento}

As autoras agradecem o financiamento recebido pela Coordenação de Aperfeiçoamento de Pessoal de Nível Superior (Capes).

\section{Referências}

AGUIAR, W. M. J.; OZELLA, S. Núcleos de Significação como Instrumento para a Apreensão da Constituição dos Sentidos. Psicologia Ciência e Profissão, v.1, p. 222-245, 2002.

ALVES-MAZZOTTI, A. J.; GEWANDSZNAJDER, F. O Planejamento de pesquisas qualitativas. In: __ (Org.) $\mathbf{O}$ método nas ciências naturais e sociais: pesquisas quantitativas e qualitativas. São Paulo: Pioneira, 2001. p. 145-178.

ARAÚJO, U.F. Os direitos humanos na sala de aula: a ética como tema transversal. São Paulo: Moderna, 2001

BAKHTIN, M. Marxismo e filosofia da linguagem. 12. ed. São Paulo: Hucitec, 2006.

BONOTTO, D. M. B. O trabalho com valores em educação ambiental: investigando uma proposta de formação contínua de professores. 2003. $231 \mathrm{f}$. Tese (Doutorado em Educação) - Centro de Educação e Ciências Humanas, Universidade Federal de São Carlos, São Carlos, 2003.

. Contribuições para o trabalho com valores em Educação Ambiental. Ciência \& Educação, Bauru, v. 14, n. 2, p. 295-306, 2008.

BONOTTO, D. M. B.; RODRIGUES, C. S. A dimensão estética da educação ambiental nos entendimentos e práticas de arte educadores e de professores da escola de ensino fundamental. In: ENCONTRO NACIONAL DE DIDÁTICA E PRÁTICA DE ENSINO, 15., 2010, Belo Horizonte. Anais... Belo Horizonte: UFMG, 2010.

BORNHEIM, G. Filosofia e política ecológica. Revista Filosófica Brasileira, Rio de Janeiro, v. 2, n. 1, p. 16-24, 1985. 
Educação ambiental e as dimensões cognitiva e afetiva do trabalho ...

BRAIT, B. Bakhtin, dialogismo e construção do sentido. 2. ed. Campinas: Editora da Unicamp, 2005.

BRAIT, B.; MELO, R. Enunciado/ enunciado concreto/ enunciação. In: BRAIT, B.

Bakhtin: conceitos-chave. 2. ed. São Paulo: Contexto, 2005. p. 61-78.

CARVALHO, L. M. A temática ambiental e o processo educativo: dimensões e abordagens. In: CINQUETTI, H. C. S.; LOGAREZZI, A. (Org.). Consumo e resíduo: fundamentos para o trabalho educativo. São Carlos: EdUFSCar, 2006. p. 18-41.

CEREJA, W. Significação e tema. In: BRAIT, B. Bakhtin: conceitos-chave. 2. ed. São Paulo: Contexto, 2005. p. 201-220.

DUARTE JUNIOR, J. F. O sentido dos sentidos: a educação (do) sensível. 4. ed. Curitiba: Criar, 2006.

FRONDIZI, R. ¿Qué son los valores?: introducción a la axiología. 3. ed. México: Fondo de Cultura Económica, 1977.

GÓES, M. C. R. A abordagem microgenética na matriz histórico-cultural: uma perspectiva para o estudo da constituição da subjetividade. Cadernos Cedes, Campinas, v. 20, n. 50, p. 9-25, 2000.

GOERGEN, P. Educação e valores no mundo contemporâneo. Educação e Sociedade, Campinas, v. 26, n. 92, p. 983-1011, 2005. Número especial.

GONÇALVES, C. W. P. Os (des)caminhos do meio ambiente. 6. ed. São Paulo: Contexto, 1998.

GRÜN, M. Ética e educação ambiental: a conexão necessária. Campinas: Papirus, 1996.

GUIMARÃES, M. Educação ambiental crítica. In: LAYRARGUES, P. P. (Org.). Identidades da educação ambiental brasileira. Brasilia: Ministério do Meio Ambiente, 2004. p. 25-34.

HERMANN, N. Estetização do mundo da vida e sensibilização moral. Educação e Realidade, Porto Alegre, v. 30, n. 2, p. 35-47, jul/dez. 2005.

LEFF, E. Educação ambiental e desenvolvimento sustentável. In: REIGOTA, M. (Org.). Verde cotidiano: o meio ambiente em discussão. Rio de Janeiro: DP\&A, 1999. p.111-129.

LIMA, G. F. C. Educação, emancipação e sustentabilidade: em defesa de uma pedagogia libertadora para a educação ambiental. In: LAYRARGUES, P. P. (Org). Identidades da educação ambiental brasileira. Brasília, Ministério do Meio Ambiente, 2004. p. 85-112.

LÜDKE, M.; ANDRÉ, M. E. D. A. Pesquisa em educação: abordagens qualitativas. São Paulo: EPU, 1986.

MANZOCHI, L. H.; CARVALHO, L. M. Educação ambiental formadora de cidadania em perspectiva emancipatória: constituição de uma proposta para a formação continuada de professores. Pesquisa em Educação Ambiental, São Carlos, v. 3, p. 103-124, 2008.

MARIN, A. A educação ambiental nos caminhos da sensibilidade estética. Revista InterAção, Goiânia, v. 2, n. 31, p. 277-290, jul./dez. 2006. Disponível em: < https://www.revistas. ufg.br/interacao/article/view/1260>. Acesso em: 26 fev. 2016. 
MARTINS, I.; NASCIMENTO, T. G.; ABREU, T. B. Clonagem na sala de aula: um exemplo do uso didático de um texto de divulgação científica. Investigações em Ensino de Ciências, Porto Alegre, v. 9, n. 1, p. 95-111, 2004.

MARTINS, I. Dados como diálogo: construindo dados a partir de registros de observações de sala de aula. In: SANTOS, F. M. T.; GRECA, I. M. (Org.). A pesquisa em ensino de ciência no Brasil e suas metodologias. Ijuí: Editora da Unijuí, 2006. p. 297-321.

MORTIMER, E. F. Microgenetic analysis and the dynamic of explanation in science classroom. In: CONFERENCE FOR SOCIOCULTURAL RESEARCH, 3., 2000, Campinas. Anais... Campinas, 2000 p. 1-23.

MORTIMER, E. F.; SCOTT, P. Atividade discursiva nas salas de aula de ciências: uma ferramenta sociocultural para analisar e planejar o ensino. Investigações em Ensino de Ciências, Porto Alegre, v. 7, n. 3, p. 283-306, 2002.

NUCCI, L. Moralidad y emoción. In: NUCCI, L. La dimensión moral en la educación. Bilbao: Desdée, 2003. p. 167-182.

PAYÁ SÁNCHEZ, M. Naturaleza de los valores. In: OLIVEIRA, M. J.; FERREIRA, N. A. (Org.). Educação e democracia: fundamentos teóricos para uma abordagem dos valores. Salvador: Eduneb, 2008. p. 41-64.

PINO, A. Processos de significação e constituição do sujeito. Temas em psicologia, Ribeirão Preto, v. 1, n. 1, p. 17-24, Abr. 1993.

PUIG, J. M. A construção da personalidade moral. São Paulo: Ática, 1998a.

. Ética e valores: métodos para um ensino transversal. São Paulo: Casa do Psicólogo, $1998 \mathrm{~b}$.

Práticas morais: uma abordagem sociocultural da educação moral. São Paulo:

Moderna, 2004.

SANTOS, W. L. P. Aspectos sócio-científicos em aulas de química. 2002. 338 f. Tese (Doutorado em Educação) - Faculdade de Educação, Universidade Federal de Minas Gerais, Belo Horizonte, 2002.

SANTOS, W. L. P.; MORTIMER, E. F. Abordagem de aspectos sociocientíficos em aulas de ciências: possibilidades e limitações. Investigações em Ensino de Ciências, Porto Alegre, v. 14, n. 2, p. 191-218, 2009.

SMOLKA, A. L. B. Construção de conhecimento e produção de sentido: significação e processos dialógicos. Temas em psicologia, Ribeirão Preto, v. 1, n. 1, p. 7-15. Abr. 1993.

Artigo recebido em 06/05/2016. Aceito em 02/11/2016.

Endereço para contato: Unesp, Instituto de Biociências, Departamento de Educação, Avenida 24 A, n. 1515, Caixa postal 199, CEP 13506-900, Rio Claro, SP, Brasil. 